\title{
O Uso de Estratégias de Gamificação em uma Disciplina de IHC: Um Relato de Experiência
}

\author{
Paulo Miranda \\ FASI \\ UFPA \\ Cametá-PA, Brasil \\ jnr.miranda@gmail.com
}

\author{
Josué Viana \\ FASI \\ UFPA \\ Cametá-PA, Brasil \\ josuevianaf@gmail.com
}

\author{
Elison Nascimento \\ FASI \\ UFPA \\ Cametá-PA, Brasil \\ elison_cn@hotmail.com
}

\author{
Carlos Portela \\ FASI \\ UFPA \\ Cametá-PA, Brasil \\ csp@ufpa.br
}

\section{RESUMO}

A disciplina de Interação Humano-Computador (IHC) aborda os conceitos utilizados para tornar um sistema de software interativo. Neste sentido, a realização de projetos práticos permite com que os alunos possam aplicar esses conceitos e desenvolver competências técnicas na área. No entanto, apenas estes projetos não garantem que todos os alunos irão se engajar nas atividades propostas pelo professor. Este artigo apresenta um relato de experiência da adoção de elementos de gamificação na disciplina de IHC da Universidade Federal do Pará, cujo objetivo era a customização da interface do WhatsApp. Sendo assim, as atividades do projeto foram organizadas em fases a fim de que o aluno-jogador pudesse aplicar os conceitos de IHC de forma gradativa. Adicionalmente, definiram-se as pontuações, medalhas e premiação para cada fase. Esse relato apresenta os resultados obtidos e o ponto de vista do professor-facilitador (ensino) e dos alunos-jogadores (aprendizagem) em relação à gamificação da disciplina.

\section{PALAVRAS-CHAVE}

Gamificação, Interação Humano-Computador, Práticas de IHC, Aplicativo de Mensagens

\section{Introdução}

Na Universidade Federal do Pará, a disciplina de Interação Humano-Computador (IHC) é ministrada no $6^{\circ}$ semestre do curso de Bacharelado em Sistemas de Informação. Esta disciplina abrange temas primordiais para o desenvolvimento de softwares interativos, como por exemplo: Padrões de Interface, Design Centrado no Usuário, Usabilidade, entre outros.

Visando contemplar os conceitos inerentes a estes temas, o professor da disciplina propôs a realização de um projeto prático que consistiu na customização da interface do aplicativo de compartilhamento de mensagens WhatsApp (ver Subseção 2.1).

Permission to reproduce or distribute, in whole or in part, material extracted from this work, verbatim, adapted or remixed, as well as the creation or production from the content of such work, is granted without fee for non-commercial use, provided that the original work is properly credited.

IHC 2019 Workshop sobre Educação em IHC (WEIHC), Outubro 2125, 2019,

Vitória, Brasil. In Anais Estendidos do XVIII Simpósio Brasileiro sobre Fatores Humanos em Sistemas Computacionais. Porto Alegre: SBC.

(C) 2019 by the author(s), in accordance with the terms of the Creative Commons Attribution-NonCommercial 4.0 International Public License (CC BY-NC 4.0).
Posteriormente, os alunos avaliaram as interfaces propostas a partir das características de usabilidade da norma ISO/IEC 25000 [1].

No entanto, este projeto já havia sido realizado no $2^{\circ}$ semestre de 2017 [2], onde o professor da disciplina de IHC observou que uma das principais dificuldades foi obter o comprometimento dos alunos, principalmente daqueles que não possuíam afinidade com a área. Assim, buscando aumentar o engajamento e motivação dos alunos, o professor optou pela inserção de estratégias de Gamificação [3] na oferta posterior da disciplina de IHC.

Em [4], Marques e Melo apresentam uma abordagem interdisciplinar para ensinar IHC com foco na avaliação de sistemas interativos, de caráter mais prático. Desta forma, optaram pela realização de trabalho prático a fim de motivar os alunos e despertar o interesse para a avaliação da qualidade de uso de sistemas. Prates [5] enfatiza que envolver sistemas reais e conhecidos pelos alunos funciona como um fator motivador que permite associar o trabalho prático da disciplina de IHC à avaliação.

Neste contexto, este artigo apresenta o relato de experiência das atividades avaliativas conduzidas nessa disciplina por meio do uso de estratégias de gamificação, a fim de comparar o desempenho e comprometimento dos alunos da turma do $2^{\circ}$ semestre de $2018 \mathrm{com}$ a da turma anterior ( $2^{\circ}$ semestre de 2017). Essa comparação se dar a partir do resultado do design proposto para o aplicativo WhatsApp. O relato é descrito a partir do ponto de vista do professor da disciplina (didática de ensino) e do feedback dos alunos (percepção de aprendizagem) em relação às estratégias de gamificação adotadas.

Além desta seção introdutória, na Seção 2 são abordados os conceitos e práticas da Interação Humano-Computador, características de Usabilidade. Adicionalmente, são descritas as estratégias de gamificação adotadas na disciplina. Já na Seção 3 são apresentadas as atividades avaliativas relacionadas à customização da interface do WhatsApp e à gamificação da disciplina. A Seção 4 relata os resultados obtidos, a partir das interfaces propostas e da análise do impacto do uso das estratégias de gamificação no engajamento e motivação dos alunos. Por fim, a Seção 5 apresenta as conclusões do artigo, as dificuldades encontradas, além dos trabalhos futuros desta pesquisa.

\section{Referencial Teórico}

\subsection{IHC e Usabilidade}


Segundo Barbosa e Silva [6], a IHC se refere às formas com que o homem interage com o computador, bem como as teorias e técnicas de projeto utilizadas para tornar um sistema interativo. Neste sentido, deve-se aplicar conceitos de design de interação como [6]:

- Estilos de Interação, que representam as maneiras como os usuários interagem ou se comunicam com o sistema;

- Paradigmas de Interação, que define a ordem com que os usuários acionam os elementos dispostos na aplicação a fim de realizar uma tarefa;

- Tipos de Interface, que se refere a busca por uma interface confortável, segura, amigável e que repasse sensação de bemestar aos usuários;

- Guidelines, que descrevem o conjunto de orientações e procedimentos utilizados para guiar o usuário em uma atividade.

Adicionalmente, o uso adequado das práticas de IHC permite desenvolver sistemas com uma boa usabilidade. A usabilidade é definida como a capacidade de um produto de software de ser compreendido, aprendido, operado, e atrativo ao usuário, quando utilizado sob condições específicas [7].

Neste sentido, a norma ISO/IEC [1] define quatro características de usabilidade: a Inteligibilidade, que consiste na capacidade de o sistema possibilitar ao usuário compreendê-lo, para realização de tarefas, sob condições de uso específicas; a Apreensibilidade, que define a capacidade de o sistema possibilitar ao usuário aprender sua aplicação facilmente; a Operacionalidade, que consiste na capacidade de o sistema possibilitar ao usuário operá-lo e controlálo; a Atratividade, que define a capacidade do produto de software de ser atraente quanto ao uso.

\subsection{Gamificação}

Gamificação consiste na inclusão de mecânica, estilo, pensamento e técnicas de design de jogos eletrônicos para engajar pessoas na resolução de um determinado problema [3]. Klock, Gasparini e Marcelo [8] destacam o uso de estratégias como bonificação, ranking, desafios, ganho de medalhas e troféus, são alguns exemplos de gamificação utilizados em jogos digitais e que podem ser incorporados em sala de aula, com o objetivo de motivar e engajar os alunos no desenvolvimento das atividades. Tais estratégias são frequentemente utilizadas nos cursos de computação, a fim de auxiliar o processo de ensino-aprendizagem das variadas e complexas disciplinas.

$\mathrm{Na}$ gamificação, os elementos podem ser divididos conforme seu nível de abstração entre dinâmicas, mecânicas e componentes. No nível mais alto de abstração encontram-se as dinâmicas, que são aspectos controlados pela gamificação, mas obtidos pelos demais elementos [9]. As dinâmicas adotadas para a disciplina de IHC, alvo deste relato, foram:

- Progresso, que fornece o feedback da evolução do usuário no decorrer do tempo;

- Relacionamentos, que são as iterações sociais que o usuário tem com outros durante as atividades, como por exemplo, com membros de equipe e adversários.

As mecânicas estão no nível intermediário de abstração, sendo processos que estimulam a ação e o engajamento do usuário e são alcançados através dos componentes [9]. As mecânicas adotadas na disciplina foram:

- Competições e Cooperações, que promovem a interação entre os usuários. Enquanto na competição os alunos disputam contra outros, eles trabalham em equipe na cooperação para atingir uma meta em comum;

- Desafios, que são atividades que exigem esforço para serem resolvidas e direcionam os usuários ao principal objetivo da gamificação, como por exemplo, criar um protótipo de interface do WhatsApp regionalizado;

- Feedback, que retorna informações relevantes ao usuário sobre a gamificação a fim de gerar engajamento e motivação;

- Recompensas, que são benefícios oferecidos a fim de reconhecer o esforço.

$\mathrm{Na}$ base da gamificação estão os componentes, que são instâncias específicas das mecânicas e dinâmicas no sistema [9]. Os componentes incorporados na disciplina foram:

- Emblemas, que representam as conquistas do usuário, sendo concedidos ao alcançar alguma meta, se apresentando nesta disciplina na forma de medalhas;

- Missões, que são metas pré-definidas que possuem recompensas específicas;

- Pontos, que representam o progresso do usuário em relação às missões propostas;

- Fases, que são identificadores do progresso do usuário ao longo do tempo, baseado nas missões cumpridas;

- Ranking, que exibem o progresso do usuário, dando significado a outros componentes e contextualizando as pontuações.

\section{Gamificação da Disciplina}

\subsection{Contexto do Projeto Prático}

O uso de aplicativos tornou-se parte do cotidiano das pessoas, influenciando as diversas formas de interação e comportamentos sociais. Um exemplo dessa nova forma de agir socialmente é o WhatsApp, um aplicativo de compartilhamento de mensagens através de textos, áudios, vídeos, documentos, imagens e emojis. Esse aplicativo permite a seus usuários comunicação em tempo real para fins pessoais e profissionais [10].

Contudo, diante de sua internacionalização, o WhatsApp não possui características específicas de uma região em seu design de interação, o que poderia intensificar a experiência de uso. Sendo assim, como projeto prático da disciplina de IHC, solicitou-se aos alunos que reformulassem a interface deste aplicativo, utilizando práticas de IHC, a fim de inserir elementos regionais e culturais da cidade de Cametá, no estado do Pará.

\subsection{Fases e Pontuação}

As atividades da disciplina foram organizadas em fases a fim de que o aluno-jogador pudesse seguir um caminho pré-estabelecido de ensino-aprendizagem. Assim, cada fase possuía um grau de dificuldade e pontuação de acordo com a ementa e objetivos da disciplina. As fases e pontuações são descritas na Tabela 1. 
O Uso de Estratégias de Gamificação em uma Disciplina de IHC: Um Relato de Experiência

Tabela 1 - Fases e Pontuação da Disciplina

\begin{tabular}{|c|c|l|}
\hline Etapa & Pontuação & \multicolumn{1}{|c|}{ Objetivo } \\
\hline Fase 1 & 4,0 pontos & $\begin{array}{l}\text { Elaborar um Projeto de Interface do } \\
\text { WhatsApp Paraense. }\end{array}$ \\
\hline Fase 2 & 3,0 pontos & $\begin{array}{l}\text { Criar Protótipos de Telas que sigam } \\
\text { as recomendações do Projeto de } \\
\text { Interface. }\end{array}$ \\
\hline Fase 3 & 3,0 pontos & $\begin{array}{l}\text { Realizar Avaliação de Usabilidade } \\
\text { dos protótipos de telas seguindo os } \\
\text { princípios da ISO/IEC 25000. }\end{array}$ \\
\hline
\end{tabular}

Assim, a Fase 1 consistiu na definição do design de interação e da interface do aplicativo, partindo da criação da logo, definição das cores, ícones, paradigmas de interação e estilos. O professor sugeriu aos alunos que estes escolhessem uma palavra do vocabulário regional para dar nome ao aplicativo proposto que remetesse a diálogo. De modo complementar, recomendou a utilização de cores que remetessem à região ribeirinha cametaense, assim como palavras do vocabulário regional em menus e/ou mensagens de resposta do sistema.

Em relação a inteligibilidade, o professor sugeriu a utilização de ícones e cores significativas que permitam proporcionar um bom discernimento aos usuários. Quanto a apreensibilidade, recomendou o uso de metáforas nos ícones do aplicativo. Quanto a operacionalidade, sugeriu a inserção de janelas de diálogos e de confirmação. Por fim, relacionado a atratividade o professor recomendou a utilização de cores equilibradas e suaves para a interface dos aplicativos, além da adequação regional das informações disponibilizadas ao usuário.

Na Fase 2 houve a criação do protótipo funcional do aplicativo proposto, utilizando métodos de regionalização do WhatsApp, através da ferramenta JustinMind ( $w w w$.justinmind.com/). Já na Fase 3, o professor solicitou aos alunos para que cada equipe avaliasse os protótipos umas das outras. Dessa maneira, elaborouse um formulário de avaliação, fundamentado nos critérios da norma ISO/IEC 25000 [1], conforme mostra a Tabela 2. Para as opções de respostas, utilizou-se a escala Likert (variando de 0 a 4 ).

Tabela 2 - Formulário de Avaliação de Interfaces

\begin{tabular}{|l|l|}
\hline \multicolumn{1}{|c|}{ Atributo } & Pergunta e Respostas \\
\hline \multirow{5}{*}{ Inteligibilidade } & Qual o grau de inteligibilidade do aplicativo? \\
& 0. Não Apropriado \\
& 1. Vagamente Apropriado \\
& 2. Parcialmente Apropriado \\
& 3. Largamente Apropriado \\
& 4. Totalmente Apropriado \\
\hline \multirow{5}{*}{ Apreensibilidade } & Qual o grau de adequação das funcionalidades \\
& do aplicativo para o aprendizado do usuário? \\
& 1. Não Adequadas \\
& 2. Parcialmente Adequadas \\
& 3. Largamente Adequadas \\
& 4. Totalmente Adequadas \\
\hline
\end{tabular}

WEIHC'19, Outubro, 2019, Vitória, ES - Brasil

\begin{tabular}{|c|c|}
\hline Operacionalidade & $\begin{array}{l}\text { O aplicativo permite controle e tolerância a } \\
\text { erros? } \\
\text { 0. Não Permite } \\
\text { 1. Permite Vagamente } \\
\text { 2. Permite Parcialmente } \\
\text { 3. Permite Largamente } \\
\text { 4. Permite Totalmente }\end{array}$ \\
\hline Atratividade & $\begin{array}{l}\text { Qual o grau de atratividade do aplicativo, } \\
\text { considerando os estilos de interação? } \\
\text { 0. Não Atrativo } \\
\text { 1. Vagamente Atrativo } \\
\text { 2. Parcialmente Atrativo } \\
\text { 3. Largamente Atrativo } \\
\text { 4. Totalmente Atrativo }\end{array}$ \\
\hline
\end{tabular}

\subsection{Desafios Propostos}

O desafio da disciplina consistiu em trabalhar com uma equipe de 5 alunos com perfil multidisciplinar (1 gerente de projetos, 1 analista de requisitos e 3 designers), aleatoriamente formada pelo professor a partir da identificação dos perfis dos alunos, a fim de regionalizar um aplicativo de compartilhamento de mensagens. Essa regionalização fora feita a partir da aplicação de práticas de IHC, especificadas através de fases. Cada uma dessas fases premiou a equipe vencedora com um artefato que proporcionou vantagem competitiva a esta na fase seguinte.

\subsection{Medalhas}

A conclusão de cada fase deu direito a uma medalha correspondente ao seu grau de dificuldade. Essas medalhas fizeram referência aos aplicativos desenvolvidos nas ofertas anteriores da disciplina de IHC [2]. Assim, a Tabela 3 apresenta as medalhas criadas para a gamificação da disciplina.

Tabela 3 - Medalhas da Disciplina

\begin{tabular}{|l|l|}
\hline Medalha & \multicolumn{1}{|c|}{ Descrição } \\
\hline & $\begin{array}{l}\text { Medalha adquirida pela equipe que concluísse a } \\
\text { Fase 1. Mensagem: Parabéns, você ganhou a } \\
\text { medalha "Ispia". Essa expressão significa } \\
\text { "Veja" ou "Olhe". }\end{array}$ \\
\hline $\begin{array}{l}\text { Medalha adquirida pela equipe que concluísse a } \\
\text { Fase 2. Mensagem: Parabéns, você ganhou a } \\
\text { medalha "DuPará". Essa expressão significa } \\
\text { "Do (estado) Pará". }\end{array}$ \\
\hline $\begin{array}{l}\text { Fodararente } \\
\text { Fase 3. Mensagem: Parabéns, você ganhou a } \\
\text { medalha "FalaParente". Essa expressão } \\
\text { representa um costume do cametaense em } \\
\text { chamar "qualquer um" de parente. }\end{array}$ \\
\hline
\end{tabular}




\begin{tabular}{l|l|} 
Medalha adquirida pela equipe que concluísse a \\
Fase 4. Mensagem: Parabéns, você ganhou a \\
medalha "Nem te conto!". Essa expressão é \\
usada no Pará antes de "se contar algo a \\
alguém" ou que demonstra que você "quer \\
contar alguma coisa a alguém".
\end{tabular}

\subsection{Resultados Obtidos}

Esta subseção apresenta os protótipos desenvolvidos durante a gamificação da disciplina de IHC. Assim, na Fase 1, obteve-se as seguintes propostas de logos apresentadas na Figura 1.
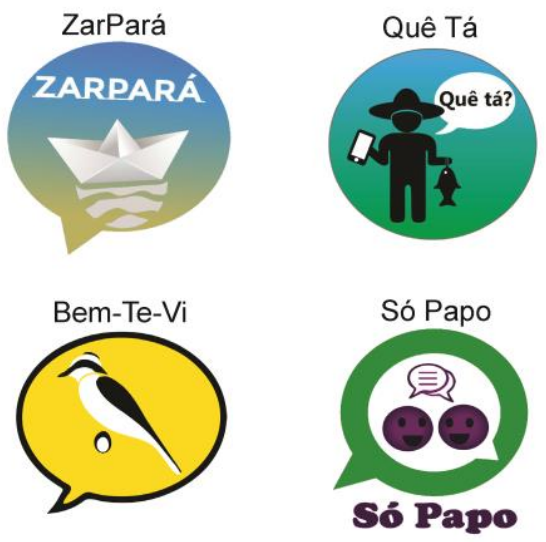

Figura 1. Logos e Nomes dos Aplicativos

A primeira equipe, Zarpará, destacou em sua logo o principal meio de transporte do ribeirinho cametaense (um barco). Adicionalmente, no nome do aplicativo, utilizou a junção de duas palavras: "Zarpar" e "Pará", insinuando metaforicamente que as mensagens do aplicativo naveguem, via embarcação, entre os usuários. A segunda equipe utilizou o nome Quê tá (Que tal?), uma saudação tradicional dos habitantes de ilhas, metaforicamente representando o trocadilho do WhatsApp, "What's Up" (“e aí?” ou "o que tá pegando?"). Em sua logo, representaram um ribeirinho segurando um peixe ao mesmo tempo em que utiliza um smartphone. Desta forma, buscaram indicar a atual situação dos povoados ribeirinhos, onde a tecnologia da informação já é cotidiano junto às tarefas das pessoas dessa região.

A terceira equipe, Bem-te-vi, inseriu em sua logo a imagem do pássaro bem-te-vi dentro de um balão, lembrando o ditado popular "Um passarinho me contou". As cores utilizadas na logo lembram as cores do pássaro. A última equipe, Só Papo, utilizou-se de uma gíria popular regional no nome do aplicativo, que quer dizer "Você está de conversa mole". Além disso, aplicou em sua logo a fruta de maior fama na região do Baixo Tocantins, o açaí, mostrando dois caroços da fruta como se estivessem conversando. A cor roxa do açaí foi usada nos caroços e no nome do sistema.

Durante a etapa de criação das logos, o professor forneceu feedback às equipes quanto ao uso de práticas de IHC. Desta forma, a equipe Zarpará, após feedback, atualizou sua logo adotando padrões de cores em gradiente (baseados nos rios da região) ao fundo em lugar do azul sólido, além de melhorar o acabamento no ícone do barco e inserir o nome do aplicativo dentro do balão, conforme mostra a Figura 2.

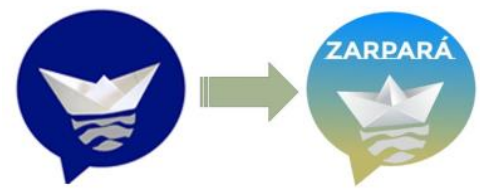

Figura 2 - Atualização da Logo do Zarpará

A equipe Quê tá foi a que mais realizou atualizações em sua logo. Inicialmente, a equipe nomeou o aplicativo de "Eras" (expressão popular que indica exclamação como o "Égua!", bastante usado no Pará). No entanto, conforme indicou o professor, este nome não representava o objetivo do aplicativo. Este fato ocasionou a mudança da logo e do nome do aplicativo, conforme mostrado na Figura 3.

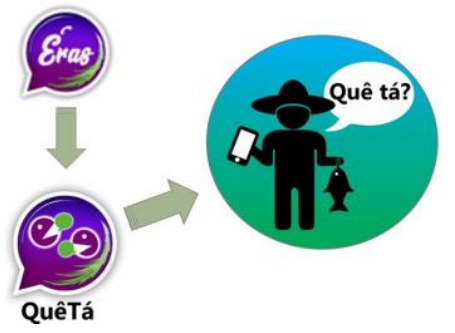

Figura 3 - Atualizações de Nome e Logo da Equipe Quê tá

Na Fase 2, a equipe Quê tá, utilizou elementos de adaptação regionais nos ícones de "conversas" e "status" (usados no WhatsApp) com variâncias das palavras tradicionais ribeirinhas "Prosas" e "Causos". Também utilizou-se um ícone de menu com três peixes, ao invés de três barras, ícone de pesquisa com uma vara de pescar e elementos funcionais, como o opcional de mostrar-se online e marcar todas as conversas como lidas. Além disso, destacase o uso harmonioso das cores conforme mostrado na Figura 4.
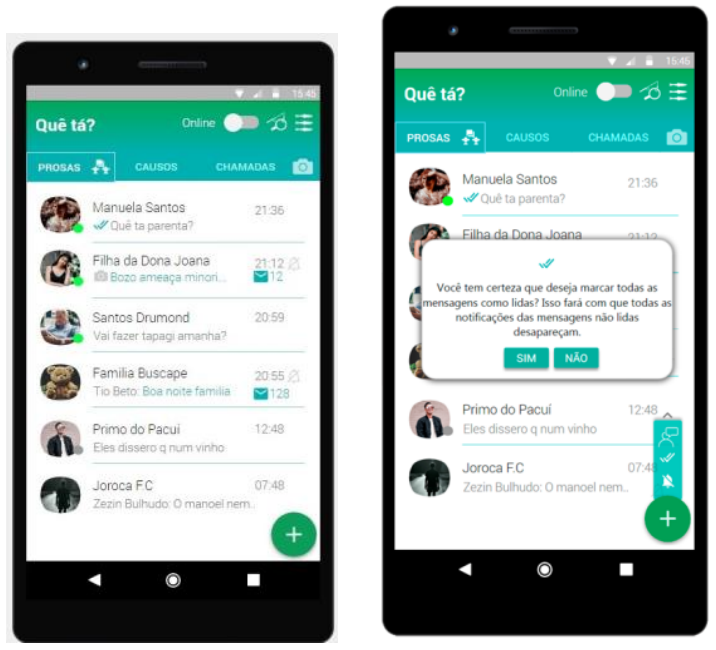

Figura 4 - Protótipos de tela equipe Quê tá 
O Uso de Estratégias de Gamificação em uma Disciplina de IHC: Um Relato de Experiência

Por outro lado, a equipe Bem-te-vi se utilizou de elementos básicos e pouco inovadores em seus protótipos funcionais do aplicativo, apenas diferenciando pela escolha dos nomes das telas de conversa e status, usando os nomes "Papos" e "Espia" nos respectivos lugares destes, como mostrado na Figura 5.

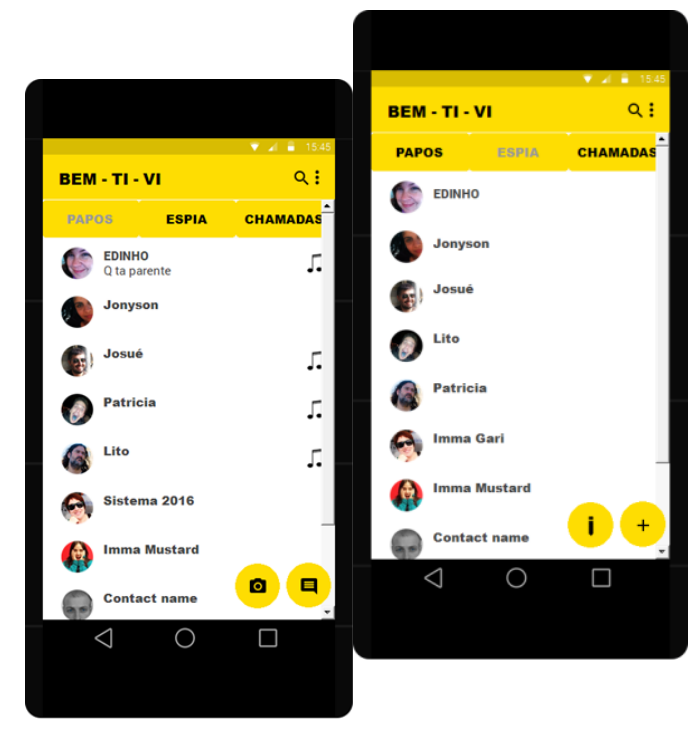

Figura 5 - Protótipo de telas equipe Bem-te-vi

Os aplicativos mais bem avaliados pela turma foram o Quê tá e Zarpará. Ambos os aplicativos foram avaliados como aderentes as características de usabilidade da norma ISO/IEC 25000 [1]. O professor destacou que essas equipes foram eficientes na adoção das práticas de IHC, principalmente no que se diz respeito aos estilos de interação e princípios de usabilidade empregues. De forma complementar, mencionou que o diferencial dessas equipes foi a criatividade na criação da identidade visual dos aplicativos.

\subsection{Premiações e Ranking}

O ranking da disciplina foi gerado a partir da nota da pontuação + classificação obtida em cada fase. Assim, existindo 4 equipes, a que melhor concluiu a Fase 1 obteve 4,0 pontos $+0,4$ pela classificação. A que ficou em $2^{\circ}$ na fase teve somado a pontuação $+0,3$ pela classificação, a que ficou em $3^{\circ}+0,2$ e a que ficou em $4^{\circ}+0,1$.

Além disso, a classificação da melhor equipe nessas fases deu direito a um artefato (recompensas) que possuía exemplos de como realizar as próximas fases, oferecendo assim uma vantagem competitiva aos vencedores. Desta forma, as outras equipes deveriam se esforçar mais para continuarem competindo.

Assim, a equipe vencedora da Fase 1 obteve um exemplo completo de projeto de interface; a vencedora da Fase 2 um artigo sobre a regionalização do WhatsApp [2]; a vencedora da Fase 3 um TCC sobre avaliação de usabilidade. Por fim, a equipe melhor colocada no ranking, ao final da disciplina ganhou uma pizza GG e um refrigerante de 2 litros.

O ranking era atualizado ao final da entrega (apresentação) de cada fase, através do site http://carlosportela.com.br/gamihc.
WEIHC'19, Outubro, 2019, Vitória, ES - Brasil

Assim, os alunos podiam acompanhar a sua classificação. Quanto aos resultados das fases, após cada apresentação, o professor atribuía uma nota (de acordo com a pontuação máxima de cada fase) e definia uma classificação de acordo com o uso das práticas de IHC e da apresentação da equipe. Os resultados de cada fase e a classificação final por equipe são apresentados na Tabela 4 .

Tabela 3 - Resultados das Equipes por Fases

\begin{tabular}{|c|c|c|c|c|c|}
\hline$\#$ & Fase 1 & Fase 2 & Fase 3 & FINAL & Pontuação \\
\hline $1^{\circ}$ & $\begin{array}{c}\text { Bem-te- } \\
\text { vi }\end{array}$ & Zarpará & $\begin{array}{c}\text { Quê tá / } \\
\text { Zarpará }\end{array}$ & Zarpará & $28,35 \mathrm{pts}$ \\
\hline $2^{\circ}$ & Zarpará & Quê tá & Só Papo & Quê tá & $26,5 \mathrm{pts}$ \\
\hline $3^{\circ}$ & Quê tá & $\begin{array}{c}\text { Bem-te- } \\
\text { vi }\end{array}$ & $\begin{array}{c}\text { Bem-te- } \\
\text { vi }\end{array}$ & Bem-te-vi & $21,85 \mathrm{pts}$ \\
\hline $4^{\circ}$ & Só Papo & Só Papo & - & Só Papo & $18,88 \mathrm{pts}$ \\
\hline
\end{tabular}

\section{Relato de Experiência}

\subsection{Professor-Facilitador (Ensino)}

Inicialmente, o professor analisou a ementa da disciplina de IHC e selecionou os tópicos Padrões de Interface, Design de Interação e Usabilidade. A fim de que os alunos pudessem aplicar esses conceitos de maneira prática, o professor estabeleceu a proposta de projeto apresentada na Subseção 3.1 e as 3 fases descritas na Tabela 1. Buscando contemplar os tópicos da ementa, definiu um percurso gradativo de dificuldade, partindo da elaboração de um projeto de interface, criação de protótipos de tela e realização de avaliação de usabilidade.

De acordo com o professor, foi a primeira vez que ele aplicou estratégias de gamificação na disciplina de IHC. No entanto, já havia realizado o projeto prático de customização da interface do WhatsApp em duas ofertas anteriores de IHC e aplicado gamificação em duas disciplinas da área de programação. Desta forma, atuou como um facilitador no processo de ensinoaprendizagem, fornecendo uma determinada de orientação para que os alunos entendessem como aplicar as teorias de IHC. Neste contexto, algumas equipes assimilaram uma postura mais proativa e outras não, ficaram aguardando mais orientações. Neste sentido, o professor forneceu feedback, buscando viabilizar a aprendizagem dos alunos sem gerar forte influência nas decisões das equipes, ou seja, não deveria desviar os alunos de encontrar por si mesmos a "solução correta". Por exemplo, na Fase 1, o professor alertou aos alunos que o nome "Eras" não remetia ao objetivo do aplicativo (comunicação), mas não sugeriu um novo nome, ficando o processo criativo para a equipe.

Quanto às medalhas, o professor aproveitou esse componente de gamificação para referenciar as propostas apresentadas nas ofertas passadas das disciplinas [2]. Ele pôde observar que estas foram uma motivação a mais para os alunos, gerando uma competição para ver quem conseguia mais medalhas. 


\subsection{Aluno-Jogador (Aprendizagem)}

Em relação às expectativas levantadas quanto à disciplina pela turma, os alunos alegaram que imaginavam que a disciplina adotaria o dinamismo tradicional de ensino, isto é, uma metodologia na qual o professor ensinaria os princípios de IHC e aplicaria avaliações com provas e trabalhos acadêmicos. Conforme relato de alguns alunos, a competição e medalhas foram diferenciais importantes para o aproveitamento da disciplina, enriquecendo o interesse por aprendizado em IHC e despertando vocações de trabalho na área de alguns alunos da turma.

De acordo com os alunos, o processo de ter que pesquisar sobre práticas de IHC e sobre a cultura de sua cidade, a fim de criar a identidade visual do aplicativo, foi desafiador a todos da turma, pois estavam acostumados com o professor repassando o conteúdo em sala de aula. Analisaram que a abordagem tradicional, normalmente, desperta o interesse apenas de alguns (aqueles que possuem maior inclinação pela área de IHC). Entretanto, os demais acabam se acomodando ou não mostrando motivação e engajamento. Nessa experiência com gamificação, observaram que todos assumiram uma postura mais proativa. Destacaram que se sentiram motivados, pois a disciplina definiu 3 fases, exigindo empenho e dedicação de cada membro da equipe, uma vez que cada uma dava direito a um prêmio (vantagem competitiva). Ressaltaram que, neste processo, o professor sempre contribuía quando surgiam dúvidas em relação à execução das atividades.

Por fim, os alunos destacaram que o resultado final revelou-se justo, uma vez que as equipes mais dedicadas no cumprimento das atividades foram as que obtiveram o maior número de medalhas, ocuparam as primeiras posições do ranking e, consequentemente, conseguiram os maiores conceitos (notas) na disciplina.

\section{Considerações Finais}

Este artigo apresentou um relato de experiência da adoção de estratégias de gamificação em uma disciplina de IHC. Descreveram-se essas estratégias a partir das fases e desafios, medalhas, pontuação e ranking, assim como as metodologias de avaliação aplicadas na disciplina. Adicionalmente, o professor descreveu a adoção destas estratégias com foco no ensino, assim como os alunos relataram sua experiência focando a aprendizagem.

As principais dificuldades relatadas foram relacionadas à mudança de paradigmas de ensino-aprendizagem, pois a maioria dos alunos e professores já estão acostumados com o método tradicional. Neste sentido, o professor destacou a necessidade de selecionar as estratégias de gamificação e preparar os materiais de apoio, como modelos de documentação e prêmios. No entanto, ele considerou esse esforço análogo ao de criar o material de uma disciplina tradicional pela primeira vez, destacando semelhanças como: pesquisa e estudo de fontes bibliográficas, definição dos exercícios (desafios) e métodos de avaliação (pontuação). Outra dificuldade relatada foi o balanceamento da quantidade de orientação dada aos alunos para que não pudesse impactar no resultado da gamificação.

Já os alunos relataram que a desmotivação quanto ao método tradicional de ensino é comum entre eles. Com a utilização da prática de gamificação, reconheceram que a disciplina se tornara mais atrativa em relação às demais do curso de Sistemas de Informação. Conforme alguns relatos, sentiram dificuldades na busca por conformidades na norma ISO/IEC 25000. No entanto, eles destacaram que a utilização dos elementos de gamificação contribuiu de forma muito significativa para uma maior dedicação e participação de todos nas atividades em sala de aula, pois estimulam a busca pelo cumprimento de desafios e metas propostas pelo professor.

A próxima etapa desta pesquisa será a reoferta da disciplina, no primeiro semestre de 2020, a fim de coletar dados e comparar os resultados obtidos entre duas turmas. Desta forma, serão analisadas as diferenças entre os perfis dos alunos e o impacto destes na adoção da gamificação.

\section{REFERÊNCIAS}

[1] ISO/IEC 25000:2011, Software engineering -- Product quality, http://iso25000.com/index.php/en/iso-25000-standards/iso-25010.

[2] Carlos Portela, Elison Nascimento and Enio Monteiro. O Uso de Práticas de IHC na Regionalização de um Aplicativo de Compartilhamento de Mensagens. In Proceedings of the IX Workshop sobre Ensino de IHC (WEIHC '18). Belém, PA, Brazil.

[3] Gabe Zichermann and Christopher Cunningham. 2011. Gamification by Design: Implementing Game Mechanics in Web and Mobile Apps (1st. ed). O'Reilly Media, Inc.

[4] Anna Marques and Áurea Melo. 2015. Relato de experiência no ensino de IHC em nível de graduação através de uma abordagem interdisciplinary. In Proceedings of the VI Workshop sobre Ensino de IHC (WEICH '15). Salvador, BA, Brazil, 13-16.

[5] Raquel Prates. 2013. Relato de Experiência de Ensino de IHC. In Proceedings of the IV Workshop sobre Ensino de IHC (WEIHC '13). Manaus, AM, Brazil, 3740.

[6] Simone Barbosa and Bruno Silva. 2010. Interação Humano-Computador. Editora Campus-Elsevier.

[7] Natasha Valentim, Káthia Oliveira and Tayana Conte. 2012. Definindo uma Abordagem para Inspeção de Usabilidade em Modelos de Projeto por meio de Experimentação. In Proceedings of the 11th Brazilian Symposium on Human Factors in Computing Systems. (IHC '12). Cuibá, MT, Brazil, 165-174.

[8] Ana Klock, Isabela Gasparini and Marcelo Soares. 2018 User-centered gamification: how to design, develop and evaluate it. In Proceedings of the 17th Brazilian Symposium on Human Factors in Computing Systems. (IHC '18) Minicursos. Belém, PA, Brazil.

[9] Kevin Werbach and Dan Hunter. 2016. For the Win: How Game Thinking Can Revolutionize Your Business. Wharton Digital Press, Philadelphia.

[10] WhatsApp 2019, About WhatsApp, https://www.whatsapp.com/about/. 